\title{
Differential regulation of intracellular factors mediating cell cycle, DNA repair and inflammation following exposure to silver nanoparticles in human cells
}

PV AshaRani ${ }^{1,2}$, Swaminathan Sethu², Hui Kheng Lim², Ganapathy Balaji ${ }^{1}$, Suresh Valiyaveettil ${ }^{1 *}$ and M Prakash Hande $2,3^{*}$

\begin{abstract}
Background: Investigating the cellular and molecular signatures in eukaryotic cells following exposure to nanoparticles will further our understanding on the mechanisms mediating nanoparticle induced effects. This study illustrates the molecular effects of silver nanoparticles (Ag-np) in normal human lung cells, IMR-90 and human brain cancer cells, U251 with emphasis on gene expression, induction of inflammatory mediators and the interaction of Ag-np with cytosolic proteins.

Results: We report that silver nanoparticles are capable of adsorbing cytosolic proteins on their surface that may influence the function of intracellular factors. Gene and protein expression profiles of Ag-np exposed cells revealed up regulation of many DNA damage response genes such as Gadd 45 in both the cell types and ATR in cancer cells. Moreover, down regulation of genes necessary for cell cycle progression (cyclin B and cyclin E) and DNA damage response/repair (XRCC1 and 3, FEN1, RAD51C, RPA1) was observed in both the cell lines. Double strand DNA damage was observed in a dose dependant manner as evidenced in $\gamma \mathrm{H} 2 \mathrm{AX}$ foci assay. There was a down regulation of p53 and PCNA in treated cells. Cancer cells in particular showed a concentration dependant increase in phosphorylated p53 accompanied by the cleavage of caspase 3 and PARP. Our results demonstrate the involvement of $\mathrm{NF} \kappa \mathrm{B}$ and MAP kinase pathway in response to Ag-np exposure. Up regulation of pro-inflammatory cytokines such as interleukins (IL-8, IL-6), macrophage colony stimulating factor, macrophage inflammatory protein in fibroblasts following Ag-np exposure were also observed.
\end{abstract}

Conclusion: In summary, Ag-np can modulate gene expression and protein functions in IMR-90 cells and U251 cells, leading to defective DNA repair, proliferation arrest and inflammatory response. The observed changes could also be due to its capability to adsorb cytosolic proteins on its surface.

Keywords: DNA damage, Isothermal titration calorimetry, inflammation

\section{Background}

Wide spread use of nanoparticles has increased the risk of nanoparticle induced toxic effects in the environment and in humans. The rate of exposure increased progressively over the years when engineered nanomaterials

\footnotetext{
* Correspondence: chmsv@nus.edu.sg; phsmph@nus.edu.sg ${ }^{1}$ Department of Chemistry, Faculty of Science, 3 Science Drive 3, National University of Singapore, 117543, Singapore

${ }^{2}$ Department of Physiology, Yong Loo Lin School of Medicine, 2, Medical

Drive, National University of Singapore, 117597, Singapore

Full list of author information is available at the end of the article
}

were extensively used in a variety of industries. Intentional manipulation of nanoparticle surfaces with biomolecules and chemicals to cater various applications resulted in nanomaterials with unforeseeable activity. Large scale production and improper waste disposal may elevate human exposure to them and subsequent accumulation of these nanomaterials in nature [1]. To add on to the complexity, most of the metal nanomaterials seem to be non-biodegradable and survive in nature and tissues for years [2]. Dermal or intravenous injections of 
nanomaterials for therapeutic applications directly expose human beings to nanomaterials whose in vivo activity has not been fully resolved. Recent reports in nanotoxicology suggest that the interaction and distribution patterns of these nanomaterials are diverse in different cell types [3]. In order to take the full advantage of nanotechnology, biocompatibility and the toxicology profile of nanoparticles must also be established.

Silver nanoparticles in particular, have attained more attention and are commonly used in antimicrobial agents and disinfectants from textiles, medical, pharmaceutical and electronic industries [4-6]. Rapid commercialisation of these nanoparticles was boosted by the fallacy that they are less toxic to cells and tissues than other silver salts. In reality, silver salts such as silver nitrate $\left(\mathrm{AgNO}_{3}\right)$ which release biologically active $\mathrm{Ag}^{+}$continually in aqueous media were reported to alter electron transport chain integrity and metabolic processes $[7,8]$. We have previously reported that Ag-np treated cells have limited exposure to $\mathrm{Ag}^{+}$ions as $\mathrm{Ag}$-np solution contained a negligible amount of free $\mathrm{Ag}^{+}$ions [9], despite the potential release of $\mathrm{Ag}^{+}$ions from Ag-np in cell culture. Data suggested that $\mathrm{Ag}$-np and $\mathrm{Ag}^{+}$can induce cell death in vitro through a ROS-mediated apoptotic process [10,11]. Kim et al [10] reported that $\mathrm{Ag}^{+}$induced metal-responsive metallothionein 1b (MT1b) mRNA expression in $\mathrm{AgNO}_{3}$ treated cells, but not in Ag-np treated cells. $\mathrm{Ag}^{+}$also induced oxidative stress-related glutathione peroxidase 1 (GPx1) and catalase expression to a greater extent than Ag-np. However, data showed that both $\mathrm{Ag}^{+}$and Ag-np induced comparable superoxide dismutase 1 (SOD1) expression levels and similar potency in cytotoxicity. Unanimously, $\mathrm{Ag}^{+}$appeared more toxic than Ag-np suggesting that the smaller the particles get the more toxic they become when the dose is based on mass [9-11].

The proposed mechanism for Ag-np induced toxicity as shown in our previous study [9] is via mitochondrial dysfunction, reactive oxygen species release and oxidative damage. Damage to DNA can be induced through direct binding of DNA or via oxidative damage to DNA. At cellular level, silver nanoparticles can penetrate cell membrane, be deposited at various organelles, halt cell proliferation and increase apoptosis. Silver nanoparticles are also capable of damaging ecosystem as shown in affecting development of zebrafish embryos [12] and penetrating plant system [13], causing various chromosomal aberrations to the plant cells. All these reports lack essential information on the characterisation of nanoparticles employed for the study which will be relevant from a biological perspective as well. Nanoparticles purchased from different sources have different stabilising agents and have uncertain composition and purity. Toxicity of such nanoparticles varies significantly according to their material composition and proper characterisation and accumulation of data could resolve this confusion. Chung et al have reported that surface modification of Ag-np with phosphoryl disulphide can greatly lower their cytotoxicity [14]. Nadworny et al investigated the protective and anti inflammatory capacity of Ag-np in porcine skin dermatitis [15] and in human lymphocytes [16] while experiments in rats established significant inflammatory activity [17]. These discrepancies in the nanoparticle properties demands further investigation on the toxicity of Ag-np on different human cell types. We have used human fibroblasts, IMR-90 for this purpose, as they have diverse functions like wound repair and production of cytokines [18]. They are known to play a role in wound healing process [19] which makes them a suitable model for inflammation studies. Fibroblasts are essential cell types in skin (exposure through contact) and lung tissues (exposure through inhalation) [19] and hence a suitable model. Glioblastoma cells, U251 are representative of cancer cells which are derived from brain tumours. Use of cancer cells in the study helps not only in understanding the differential response between normal and cancer cells but also provides useful information on the nanoparticle mediated therapy.

Here, we report a detailed study on the potential molecular mechanisms underlying silver nanoparticle toxicity using two different cell lines. Specific pathways involved in silver nanoparticle toxicity were explored. Our results show that Ag-np could evoke inflammatory response in cells characterised by high secretion of pro-inflammatory cytokines, as detected by enzyme linked immuno-sorbent assay (ELISA). Pathway specific assays focussing on cell cycle, DNA damage, cell adhesion and extracellular matrix and cell signalling gave vital information that can be used to assess the mode of action of Ag-np in cells.

\section{Results}

\section{Binding of cytosolic proteins with Ag-np}

Isothermal titration calorimetry (ITC) emerged as a potential tool to explore the binding of DNA, proteins and amino acids with nanoparticles. A representative heat change profile for the complexation of cytosolic proteins with starch capped Ag-np and binding of cytosolic proteins with starch is depicted in Figure 1. Endothermic nature of the peaks indicates the binding between silver nanoparticles/starch with proteins. Due to the lack of exact information on cytosolic proteins such as molecular weight, concentration of individual proteins in the mixture, and number of moles of surface nanoparticles, binding isotherms were plotted against total volume of protein added. It can be seen that a monotonic decrease in the exothermic heat of binding occurs with successive injections until saturation is reached. Heat changes observed during addition of proteins may be due to binding of nanoparticle or binding of surface starch with 


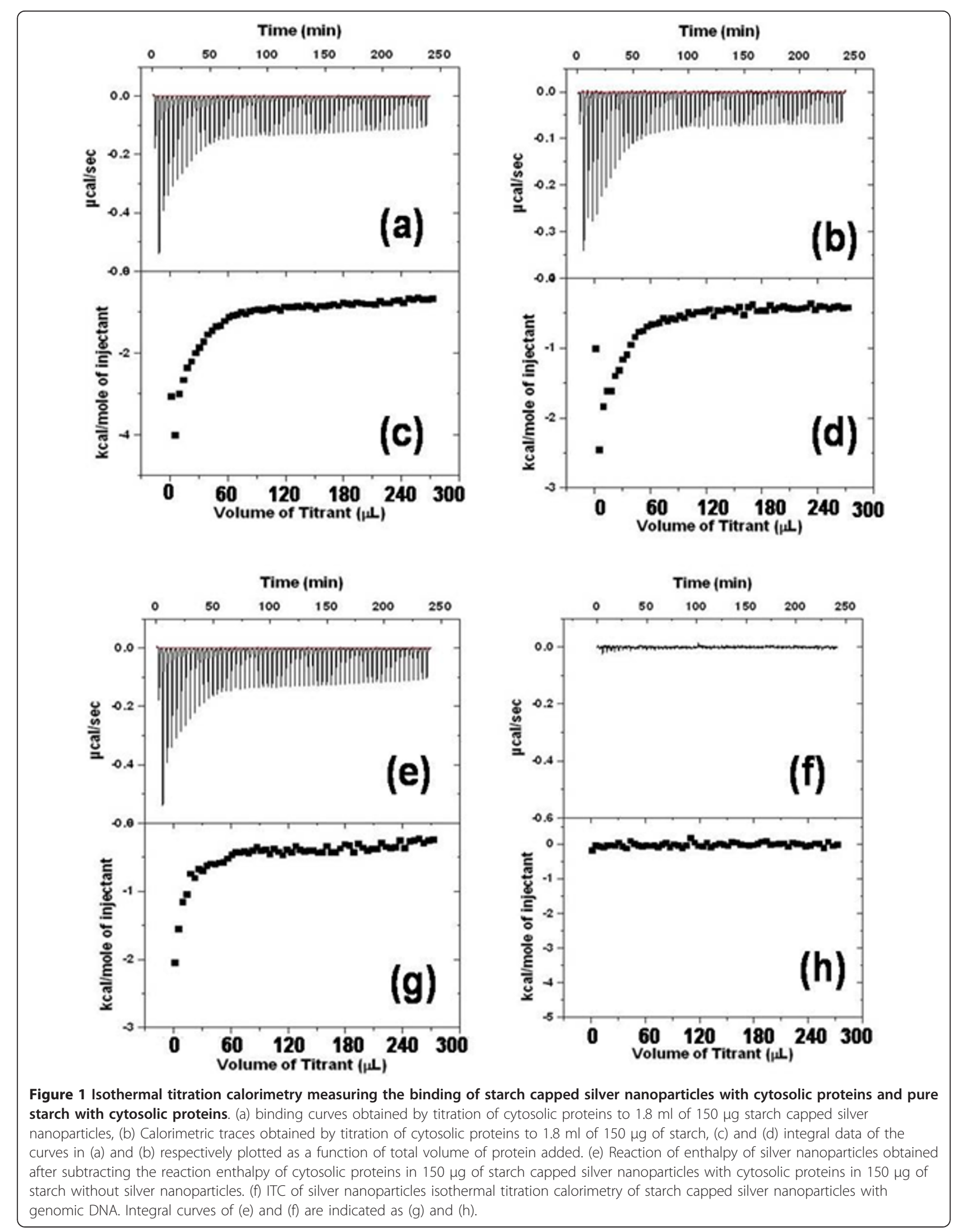


cytosolic proteins. Control experiments were performed with pure starch in order to identify their binding with cytosolic proteins.

Interestingly, ITC curves representing the titration of cytosolic proteins with starch capped Ag-np can only be fitted into a model of two sets of binding site (Figure 1a) while the ITC titration curve representing heat change for the complexation of cytosolic proteins with starch could be fitted into a model of a single set binding sites as depicted in Figure 1b. Integral data of the curves in Figure $1 \mathrm{a}$ and $1 \mathrm{~b}$ are plotted as Figure $1 \mathrm{c}$ and $1 \mathrm{~d}$ as a function of total volume of protein added to Ag-np and starch, respectively. After subtraction of the binding due to starch and integration of the corresponding heat changes over time, generated a typical sigmoidal titration curve as shown in Figure 1e which strongly support the binding of Ag-np surface with cytosolic proteins. From the Figure $1 \mathrm{f}$ it is understood that neither starch nor Ag-np were interacting with genomic DNA. Integral data of the curves in Figure $1 \mathrm{e}$ and $1 \mathrm{f}$ are plotted as Figure $1 \mathrm{~g}$ and $1 \mathrm{~h}$ as a function of total volume of protein (Figure 1g) and DNA (Figure 1h), added to Ag-np.

\section{Effect of Ag-np on gene expression}

In order to investigate the specific effects of silver nanoparticles on human cells, pathway specific gene expression profiles for cell cycle, DNA damage, cell adhesion and signalling cascades were evaluated. To assess the differential expression in a wider perspective, we have looked at these effects in both IMR 90 and U251 cells, representatives of normal cells and cancer cells respectively.

We have earlier demonstrated that Ag-np exposure affects the cell cycle process in both cells [10]. List of genes in cell cycle pathway affected by Ag-np exposure $(400 \mu \mathrm{g} / \mathrm{ml})$ and corresponding expression level changes are presented in Table 1. CDC2 was the only gene which showed a significant increase in expression in IMR90 cells, with a majority of the investigated genes down regulated (Table 1). U251 cells showed up regulation of CDK5R2, retinoblastoma $(R b)$ and Bax gene (Table 1). Gadd $45 \alpha$ in U251 cells and Gadd $45 \gamma$ in IMR90 cells were down regulated following exposure to Ag-np (Table 1). We show that there is a decrease in the protein expression of $\mathrm{p} 53$, p21, PCNA and cyclin B, which are involved in cell cycle control, following $400 \mu \mathrm{g} / \mathrm{ml} \mathrm{Ag-np} \mathrm{exposure} \mathrm{(Figure} \mathrm{2a,}$ b). Protein levels for PCNA dropped by a factor of 0.35 in fibroblasts (Figure 2a) and 0.31 in cancer cells (Figure 2b). Normal cells showed a 0.32 fold drop in p53 levels whereas cancer cells exhibited a 0.58 fold decrease. There was a 0.12 fold drop in p21 levels in normal cells corresponding to 0.72 fold in cancer cells. However, a similar drop in cyclin B levels in both the cell types $(\sim 0.41$ in normal cells and 0.42 fold in cancer cells). Low doses of Agnp resulted in a gradual decrease in p53 and PCNA levels
Table 1 Differentially expressed genes in cell cycle pathway.

\begin{tabular}{lcclcc}
\hline IMR 90 & & & U251 & \\
\hline Gene & $\begin{array}{c}\text { Genbank } \\
\text { ID }\end{array}$ & $\begin{array}{c}\text { Fold } \\
\text { change }\end{array}$ & Gene & $\begin{array}{c}\text { Genbank } \\
\text { ID }\end{array}$ & $\begin{array}{c}\text { Fold } \\
\text { change }\end{array}$ \\
\hline CDC2 & NM_001786 & 24.24 & ANAPC2 & NM_013366 & 0.33 \\
CDKN3 & NM_005192 & -0.67 & CDK5R2 & NM_003936 & 4.93 \\
PCNA & NM_182649 & -0.58 & RB1 & NM_000321 & 0.65 \\
SUM01 & NM_003352 & -0.67 & BAX & NM_004324 & 0.96 \\
UBE1 & NM_003334 & -0.69 & CDKN3 & NM_005192 & -0.87 \\
MCM2 & NM_004526 & -0.27 & CCNE1 & NM_001238 & -0.55 \\
BIRC5 & NM_001168 & -0.22 & E2F1 & NM_005225 & -0.75 \\
CCNH & NM_001239 & -0.27 & PCNA & NM_182649 & -0.78 \\
ANAPC4 & NM_013367 & -0.51 & SUM01 & NM_003352 & -0.37 \\
KPNA2 & NM_002266 & -0.37 & UBE1 & NM_003334 & -0.61 \\
CCNB1 & NM_031966 & -0.91 & MCM7 & NM_005916 & -0.90 \\
RGC32 & NM_014059 & -0.61 & CCNG2 & NM_004354 & -0.34 \\
CDC20 & NM_001255 & -0.59 & CCNB1 & NM_031966 & -0.75 \\
CCNE2 & NM_057735 & -0.40 & PKMYT1 & NM_182687 & -0.34 \\
GADD45A & NM_001924 & -0.33 & CKS1B & NM_001826 & -0.77 \\
RB1 & NM_000321 & -0.33 & CDC16 & NM_003903 & -0.21 \\
& & & MK167 & NM_002417 & -0.78 \\
& & & MAD2L2 & NM_006341 & -0.56
\end{tabular}

Gene expression changes in IMR 90 and U251cells following Ag-np exposure. All values are normalized against housekeeping genes. Fold change is calculated as treated/control - $1 *$. ${ }^{*}$ Basal levels were normalised to 0 .

(Figure 2a, b) in both the cell lines. p21 showed a concentration dependant decrease in densitometry even though the protein bands appeared same intensity in control and in treated with 50 or $200 \mu \mathrm{g} / \mathrm{mL}$ of Ag-np (Figure 2a, b). The induction of apoptotic pathway is indicated by the phosphorylation of p53, cleavage of caspase and PARP. Ag-np exposure induced phosphorylation of p53 in a dose dependent manner in cancer cells (Figure $2 \mathrm{~b}$ ) but phosphorylation was not detected in normal cells (Figure 2a). Cleavage of Caspase and PARP was observed in both cell lines (Figure 2a, b). Density of Caspase 3 and PARP fragments were measured and presented in Figure 2a, b. Data for phospho p53 and proteins involved in apoptosis pathway (Caspase and PARP) are displayed in Figure 2a, b which showed an increase in Caspase 3 cleavage in both cell types. Over expression of Caspase 3 was observed specifically in cancer cells. Normal cells showed up regulation of PARP but no cleavage. In cancer cells an increase in Caspase and PARP cleavage was observed along with increased levels of phospho p53. We have also observed a decrease in the levels of survivin following Ag-np exposure in both the cell types.

Analysis of genes involved in DNA damage and repair pathway showed significant mRNA level changes (Table 2). U251 and IMR90 cells showed differential profiles in this pathway after Ag-np exposure. There was an up regulation of GADD45 $\gamma$ in IMR90 cells with rest of the observed 


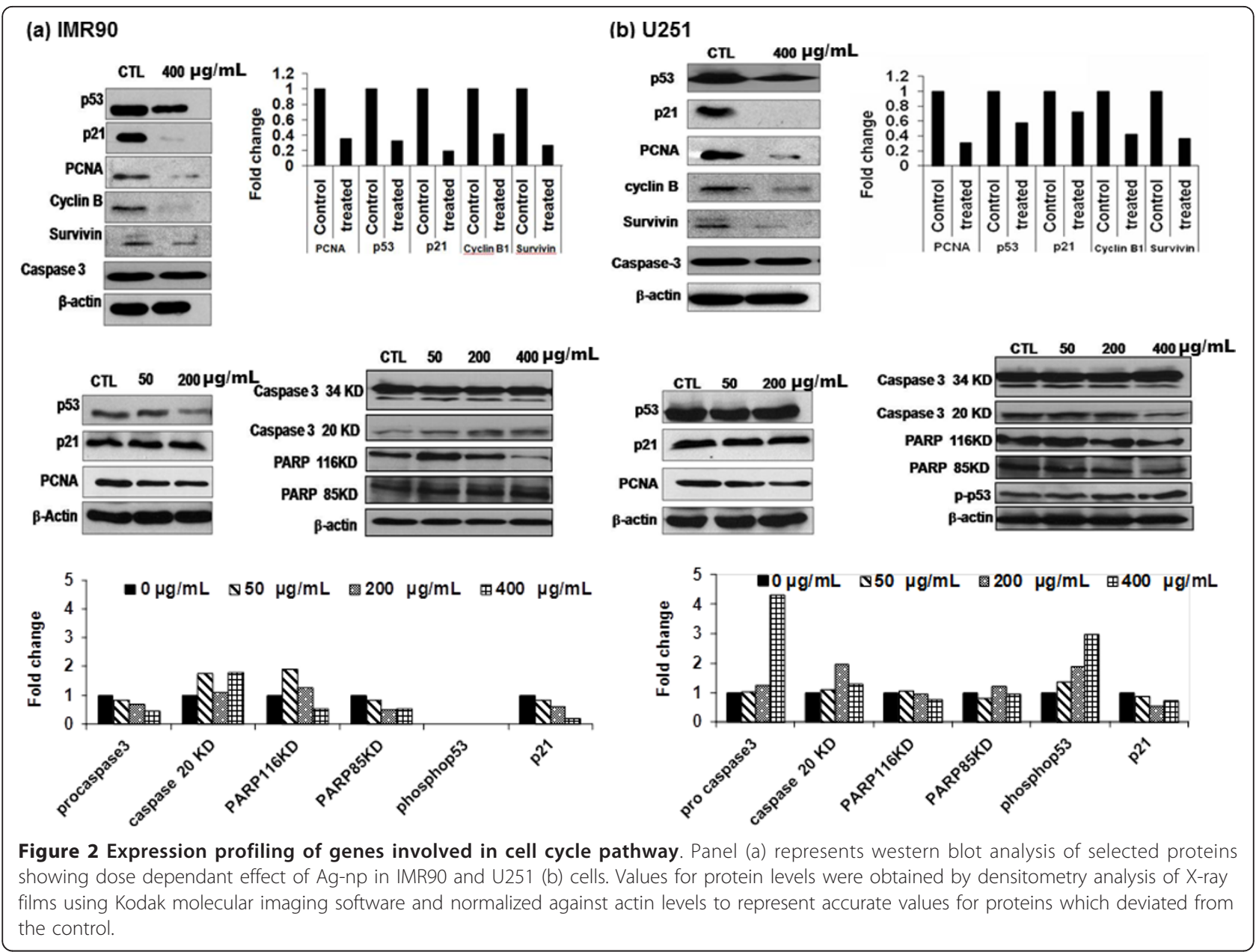

genes were down regulated. U251 cells exhibited an increase in the major DNA damage repair pathway genes like, ATM, ATR and XPA. The other important genes in this pathway like Abl1, Gml, Brca1, Zak, Xrcc5, Trex1, Pms1, Ccnu and Apex2 were also up regulated in the cancer cells. Down regulation of genes involved in base excision repair (Mbd4, Apex1, OGG1 and Mutyh) and mismatch repair pathways (Mutyh, Abl1, Pms1 and MSH2) were observed. Double strand DNA damage was further evidenced by the appearance of $\gamma \mathrm{H} 2 \mathrm{AX}$ in the nuclei of Ag-np treated cells (Figure 3a). Untreated U251 cells (Figure $3 \mathrm{~b}$ ) showed generally less number of foci compared to cells exposed to $25 \mu \mathrm{g} / \mathrm{mL}$ of Ag-np (Figure 3c), $50 \mu \mathrm{g} / \mathrm{mL}$ (Figure 3d) $100 \mu \mathrm{g} / \mathrm{mL}$ (Figure 3e) and $10 \mu \mathrm{M} \mathrm{H}_{2} \mathrm{O}_{2}$ (Figure 3f). Similar pattern was observed in untreated IMR-90 cells where untreated cells showed no foci (Figure $3 \mathrm{~g}$ ) whereas, exposure with $25 \mu \mathrm{g} / \mathrm{mL}$ of Ag-np (Figure 3h) $50 \mu \mathrm{g} / \mathrm{mL}$ (Figure 3i) $100 \mu \mathrm{g} / \mathrm{mL}$ and (Figure 3j) $10 \mu \mathrm{M}$ $\mathrm{H}_{2} \mathrm{O}_{2}$ (Figure 3k), showed multiple foci. Quantitative analysis of $\gamma \mathrm{H} 2 \mathrm{AX}$ foci assay confirmed that both IMR-90 cells and $\mathrm{U} 251$ cells showed dose dependent increase in $\gamma \mathrm{H} 2 \mathrm{AX}$ foci from 0 to $100 \mu \mathrm{g} / \mathrm{mL}$. Higher number of foci in U251 cells suggests higher susceptibility of human cancer cells to Ag-np induced double strand DNA damage (Figure 3a).

Array analyses of cell adhesion and extracellular matrix showed differential regulation of gene expression. Genes up regulated and down regulated for the same are listed in Table 3. Scge (sarcoglycan epsilon) was down regulated in both cell lines. ITGA2 and Ctnna1 were up regulated in normal cells treated with Ag-np. Additionally up regulation of integrin was observed in both cells. Transforming growth factor gene (Tgfbi), Spp1 and ITGA5 were up regulated in cancer cells. Matrix metallo peptidases like $M M P 3$ and $M M P 2$ were slightly upregulated in normal and cancer cells respectively.

Key molecules regulating signalling cascades showed up regulation following Ag-np exposure. Jun, CSF2 and $I L-8$ showed increased expression in IMR90 cells, whereas, $N F \kappa B 1, N F \kappa B I A$, FN1 (fibronectin 1), GADD45A, BIRC2, TMEPAI (prostate androgen induced RNA) and CEBPB (CCAAT/enhancer binding protein) were up regulated in cancer cells (Table 4). Gene data corresponding to cell signalling are represented in Table 4. Major signalling pathways involved in Ag-np mediated molecular response is 
Table 2 Gene expression pattern in DNA damage pathway.

\begin{tabular}{|c|c|c|c|c|c|}
\hline \multicolumn{3}{|c|}{ IMR-90 } & \multicolumn{3}{|c|}{ U251 } \\
\hline Gene & $\begin{array}{l}\text { Genbank } \\
\text { ID }\end{array}$ & $\begin{array}{c}\text { Fold } \\
\text { change }\end{array}$ & Gene & $\begin{array}{l}\text { Genbank } \\
\text { ID }\end{array}$ & $\begin{array}{c}\text { Fold } \\
\text { change }\end{array}$ \\
\hline GADD45G & NM_006705 & 6.12 & $A B L 1$ & NM_005157 & 1.69 \\
\hline BRCA1 & NM_007294 & -0.44 & GML & NM_002066 & 0.52 \\
\hline$A B L 1$ & NM_005157 & -0.39 & BRCA1 & NM_007294 & 1.89 \\
\hline GML & NM_002066 & -0.43 & ZAK & NM_016653 & 2.54 \\
\hline$X R C C 5$ & NM_021141 & -0.34 & ATR & NM_001184 & 0.21 \\
\hline MSH2 & NM_000251 & -0.28 & $X R C C 5$ & NM_021141 & 0.59 \\
\hline RAD51C & NM_058216 & -0.74 & XPA & NM_000380 & 0.91 \\
\hline ERCC3 & NM_000122 & -0.73 & TREX1 & NM_016381 & 0.51 \\
\hline OGG1 & NM_002542 & -0.45 & PMS1 & NM_000534 & 0.64 \\
\hline$X R C C 1$ & NM_006297 & -0.31 & CCNU & NM_021147 & 1.52 \\
\hline MBD4 & NM_003925 & -0.59 & APEX2 & NM_014481 & 0.29 \\
\hline APEX 1 & NM_080649 & -0.67 & ATM & NM_000051 & 1.98 \\
\hline MUTYH & NM_012222 & -0.49 & TP53 & NM_000546 & -0.28 \\
\hline PMS1 & NM_000534 & -0.64 & FEN1 & NM_004111 & -0.51 \\
\hline SUMO1 & NM_003352 & -0.69 & RAD51C & NM_058216 & -0.24 \\
\hline ATM & NM_000051 & -0.50 & PCNA & NM_182649 & -0.46 \\
\hline $\mathrm{CCNH}$ & NM_001239 & -0.77 & RPA1 & NM_002945 & -0.60 \\
\hline IGHMBP2 & NM_002180 & -0.50 & & & \\
\hline LIG3 & NM_002311 & -0.48 & & & \\
\hline APEX2 & NM_014481 & -0.29 & & & \\
\hline PCNA & NM_182649 & -0.69 & & & \\
\hline RPA1 & NM_002945 & -0.53 & & & \\
\hline
\end{tabular}

Regulation of DNA damage response genes in silver nanoparticle treated IMR 90 and U251cells. Fold change is calculated as indicated in table 1.

indicated in Table 5. The array results were further validated by RT-PCR, where an up regulation of IL- 8 mRNA levels in fibroblasts as well as down regulation of p53 (Figure 4a) was observed. MAPK1 mRNA levels were found to be higher in normal cells (Figure 4b). Exposure to nanoparticles to cancer cells showed up regulation of $\mathrm{NF} \kappa \mathrm{B}$ (Figure 4c).

\section{Inflammatory response in nanoparticle mediated cells}

The correlation between inflammation and genotoxicity has been reported earlier [20,21]. Excessive and persistent formation of reactive oxygen species from inflammatory cells (neutrophils, macrophages) during particle-elicited inflammation will generate genetic damage resulting from the oxidative DNA attack [22]. Conversely, DNA damage is also capable of inducing the release of inflammatory cytokines [23,24]. Therefore, it is essential to investigate the inflammatory properties of Ag-np which can contribute to more thorough understanding on genotoxicity induced by Ag-np.

Our study to investigate the innate ability of Ag-np to induce cytokine and chemokines production revealed that Ag-np triggered production of certain cytokines and interleukins (IL) in normal resting human fibroblasts. Of the
17 cytokines tested, only a few cytokines exhibited detectable levels in the supernatant of both Ag-np treated and untreated cells (Figure 5). There was significant increase in the production of IL- 8 , IL- 6 , ICAM-1, MCP- 1 , MIP- $1 \beta$ and GRO $\alpha$ in those cells treated with silver nanoparticles compared to that of untreated control cells (Figure 5). There was increase in the production of GM-CSF and IFN $\gamma$ in the silver nanoparticles treated cells. IL1 $\beta$, IL-2, IL-7, IL-16, IL-17, TNF $\alpha$, MIP1 $\alpha$ and RANTES levels were not detected in the culture supernatants of both treated and untreated cells.

\section{Discussion}

\section{Interaction of Ag-np with cytosolic proteins}

Nanoparticles have a greater tendency to bind with proteins forming a protein corona [25] and mimic nutrients which facilitate easy receptor mediated uptake. Nanoparticles can also adsorb agonists or antagonists and interfere with various pathways and truncate the biomolecules [25]. Here, we show that cytosolic proteins are adsorbed on to silver nanoparticle surface forming a protein-starch coating which could control cellular responses. This observation may be useful in the understanding of intracellular behaviour of Ag-np. The surface adsorption of protein limit the availability for cellular functions, but stabilise the proteins thereby inhibiting protein degradation in proteasomes [25]. This process can alter normal cell cycle progression where timely degradation of proteins is necessary for smooth transition in to cell cycle stages. Also binding to nanoparticle surface can interfere with native conformation of the proteins leading to loss of function [25]. Another outcome of nanoparticle binding is increase in activity of proteins as a result of immobilisation at surfaces [25]. It is conceivable that the affinity and binding of Ag-np with proteins vary between cell types that have tissue specific proteins which explain the altered signalling pathways operating in different cell types after nanoparticle exposure (MAPK in fibroblasts and NF $\kappa \mathrm{b}$ in cancer cells). These results set hurdles on cellular response prediction, as the identity of protein adsorbed to the nanoparticle remains unclear and the fact that the residency period and choice of protein adsorbed on to these nanoparticles varies with cell and tissue types. It is possible that Ag-np tends to have different effects on different cell types. We had reported the nuclear deposition of Ag-np in zebrafish embryos and human cells (U251) where Ag-np was seen in the nucleus of cells [12,26]. Considering the property of the nanoparticle surface which facilitates surface adsorption of proteins, we speculate that nanoparticles label cytosolic proteins which require nuclear localisation and are co-transported with them. Absence of direct interaction with genomic DNA further supports this notion. This observation has 
(a)

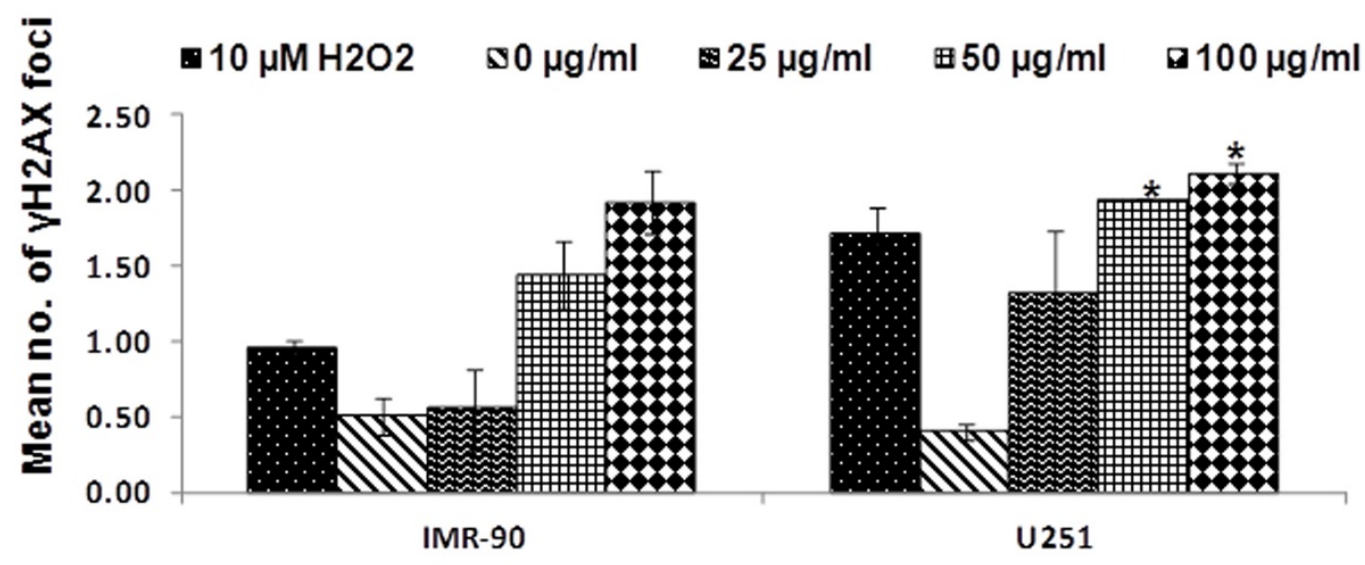

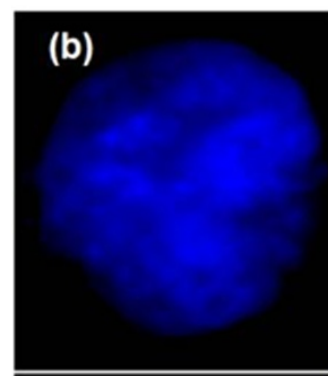

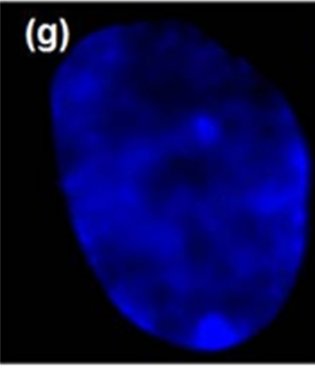

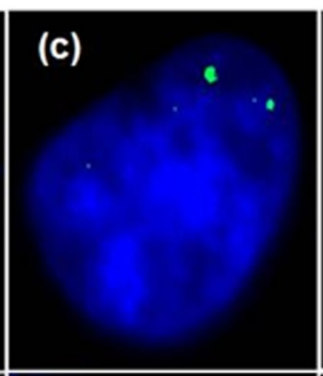

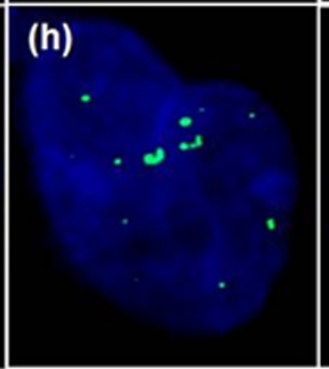

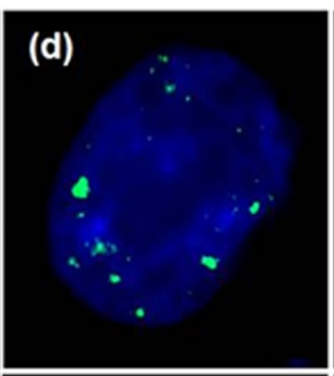

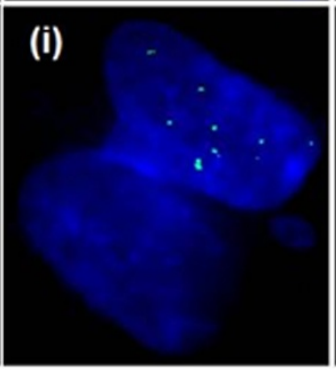

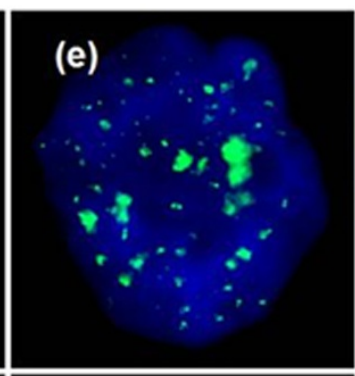

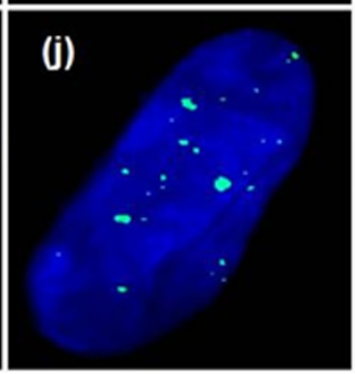

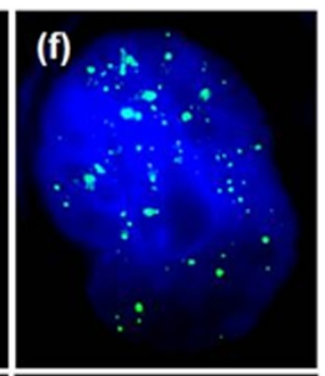

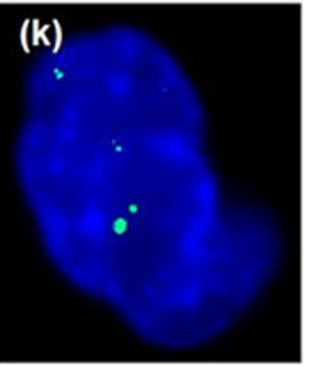

Figure 3 Altered gene expression profile in Ag-np treated cells. (a) Quantitative analysis of $\gamma \mathrm{H} 2 \mathrm{AX}$ foci showed more double strand DNA damage induced in U251 cells compared IMR-90 cells. Untreated U251 cells (b) showing minimal foci, (c) cells exposed to $25 \mu \mathrm{g} / \mathrm{mL}$ of Ag-np-3 (d) $50 \mu \mathrm{g} / \mathrm{mL}$ (e) $100 \mu \mathrm{g} / \mathrm{mL}$ and (f) $10 \mu \mathrm{M} \mathrm{H}_{2} \mathrm{O}_{2}$, showing multiple foci. (g) Untreated IMR90 cells shows no foci whereas, exposure with (h) 25 $\mu \mathrm{g} / \mathrm{mL}$ of Ag-np-3 (i) $50 \mu \mathrm{g} / \mathrm{mL}$ (j) $100 \mu \mathrm{g} / \mathrm{mL}$ and (k) $10 \mu \mathrm{M} \mathrm{H}_{2} \mathrm{O}_{2}$, shows multiple foci.

implications in nanotechnology to develop tools for nuclear targeting for cancer therapy and transfection.

\section{Effect on gene expression profiles}

Our earlier functional studies [26] and current gene expression data showed that Ag-np exposure induced cell cycle arrest at S/G2/M phase of cell cycle. This observation can be due to the changes in the expression levels of genes regulating the cell cycle process. We have observed a decrease in the expression of p53, p21, PCNA, cyclin E and cyclin B. However the cell cycle arrest seems to be independent of p21 as there was no inhibition of cdk through p21 induced G1 arrest. Gadd 45 group of proteins are over expressed in cells upon genotoxic stress [27] was also found to be significantly elevated in Ag-np treated cells (Gadd 45 $\alpha$ in cancer cells and Gadd $45 \gamma$ in fibroblasts). Gadd 45 regulates cell cycle by repressing the localization of Cyclin B1 to the nucleus. This is known to initiate $\mathrm{G} 2 / \mathrm{M}$ arrest in target cells [28]. Cdc 2, a binding partner of cyclin B proteins was down regulated in both cell types after Ag$\mathrm{np}$ exposure. Increased Cdc 2 levels may be due to the accumulation of cells in $G_{2}$ phase due to the decrease level of cyclin B seen earlier. $R b$ and $E 2 F$ form a repressive complex in $\mathrm{S}$ phase, which upon phosphorylation by cyclin $E$ releases $E 2 F$ [29]. E2F being the transcription factor for $S$ phase genes blocks cell transition through $S$ phase [29]. We have seen that in cancer cells 
Table 3 Gene expression changes in cell adhesion and extracellular matrix pathway.

\begin{tabular}{lcclcc}
\hline Gene & $\begin{array}{c}\text { IMR-90 } \\
\text { ID }\end{array}$ & $\begin{array}{c}\text { Fold } \\
\text { change }\end{array}$ & Gene & $\begin{array}{c}\text { Genbank } \\
\text { ID }\end{array}$ & $\begin{array}{c}\text { Fold } \\
\text { change }\end{array}$ \\
\hline ITGA2 & NM_002203 & 2.32 & ITGA5 & NM_002205 & 1.55 \\
CTNNA1 & NM_001903 & 1.01 & SPP1 & NM_000582 & 1.28 \\
MMP3 & NM_002422 & 0.40 & LAMA4 & NM_002290 & 0.24 \\
ITGA11 & NM_012211 & -0.83 & ADAMTS1 & NM_006988 & 0.26 \\
SGCE & NM_003919 & -0.49 & TGFBI & NM_000358 & 1.44 \\
COL6A1 & NM_001848 & -0.27 & SGCE & NM_003919 & -0.30 \\
LAMA4 & NM_002290 & -0.27 & MMP2 & NM_004530 & 0.29 \\
ADAMTS1 & NM_006988 & -0.21 & & & \\
\hline
\end{tabular}

Differential expression of genes in IMR-90 and U251 cells are indicated in the table. All values are normalised against housekeeping genes. Fold change is calculated as mentioned in table 1 .

following Ag-np exposure there was an up regulation in the expression of retinoblastoma $(R b)$ and down regulation of E2F. It is evident that the low levels of cyclin $E$ could hypo-phosporylate $\mathrm{Rb}$ and fail to release $E 2 F$ rendering them in their repressive forms resulting in $S$ phase arrest. We have also observed an up regulation of Zak proteins which are members of Mitogen activated protein kinase pathway (MAPKKK) that triggers cell cycle arrest and check point regulation following stress response. Zak has been associated with down regulation of cyclin $\mathrm{E}$ and S/G2/M arrest [30]. Therefore, we suggest that events like Zak down-regulating cyclin $\mathrm{E}$ which represses $E 2 F$ and decrease cyclin B levels by Gadd 45 resulted in the observed cell cycle arrest. Reports have already emphasized role of p53 in regulating PCNA and p21 genes [31]. Hence, down regulation of p53 is believed to be the reason for low levels of p21 and PCNA which might play a role in determining the cellular fate. Along with the down regulation of p53

Table 4 Genes differentially expressed in signal transduction pathway.

\begin{tabular}{lcclcc}
\hline IMR-90 & & \multicolumn{3}{c}{ U251 } \\
\hline JUN & $\begin{array}{c}\text { Genbank } \\
\text { ID }\end{array}$ & $\begin{array}{c}\text { Fold } \\
\text { change }\end{array}$ & Gene & $\begin{array}{c}\text { Genbank } \\
\text { ID }\end{array}$ & $\begin{array}{c}\text { Fold } \\
\text { change }\end{array}$ \\
IL8 & NM_0002228 & 3.05 & FN1 & NM_002026 & 6.76 \\
CSF2 & NM_000758 & 21.16 & JUN & NM_002228 & 0.35 \\
TFRC & NM_003234 & 0.64 & NFKB1 & NM_003998 & 26.44 \\
BMP2 & NM_001200 & 0.55 & BIRC2 & NM_001166 & 3.09 \\
BIRC2 & NM_001166 & -0.22 & GADD45A & NM_001924 & 17.24 \\
IGFBP3 & NM_000598 & -0.90 & TMEPAl & NM_020182 & 10.93 \\
IRF1 & NM_002198 & -0.30 & TFRC & NM_003234 & 1.55 \\
HK2 & NM_000189 & -0.21 & CEBPB & NM_005194 & 10.96 \\
& & & CXCL9 & NM_002416 & -0.86 \\
& & & IRF1 & NM_002198 & -0.21 \\
\hline
\end{tabular}

Fold change is calculated as mentioned in table 1. expression we also observed phosphorylation of residual p53 in treated cells probably facilitating p53 mediated effects.

Expression patterns of genes involved in DNA damage response pathway suggest that cells treated with Ag-np suffered impaired DNA repair mechanisms in normal cells and initiation of DNA repair response in cancer cells. This is evidenced by the increase in ATM and ATR levels indicating double strand DNA breaks where they act as sensors activating downstream targets for DNA repair [32]. Normal cells showed down-regulation of genes involved in base excision repair $(M b d 4$, Apex 1 , OGG1 and Mutyh), mismatch repair pathways (Mutyh, Abl1, Pms1 and MSH2) and double strand break repair pathway (ATM). These molecular results further confirm existing genotoxicity data, where DNA damage and chromosomal aberrations were observed to be higher in Ag-np treated U251 cells than IMR-90 [26]. Up regulation of Abl and Brcal genes specifically in cancer cells in contrast to that of the normal cells is a significant observation. DNA repair pathway responsible for DSBs repair such as homologous recombination (HR) is likely to be activated with up-regulation of Brcal. Non-homologous end joining (NHEJ), another major DSBs repair mechanism does not play important role in DSBs repair in our model as up-regulation of Abl will down-modulate NHEJ pathway $[33,34]$. PCNA is a co factor for DNA polymerase and an essential player in DNA synthesis and DNA repair [35]. Down regulation of PCNA following Ag-np exposure could have indicated that repair mechanisms such as base excision repair, nucleotide excision repair and mismatch repair are not essential in this study as mostly DSBs were induced.

Cell adhesion and extracellular matrix genes were not highly affected by nanoparticles exposure. However, up regulations of alpha integrins were observed in both cell lines. Integrins play vital role in signal transduction and interactions of cells with extracellular matrix. Up regulation of integrin operates protective mechanisms where cytoskeletal and ECM are challenged by extraneous factors [36]. Interestingly, an up regulation of tumour growth factor or Tgfbi was observed in treated cancer cells. However, no TGF over expression was detected in normal cells.

Signalling pathway analysis identified up regulation of jun in both cell lines which can act through JNK pathways regulating cell proliferation or cytokine production. Involvement of JNK pathway has been reported in silver nanoparticle mediated toxicity studies [37]. Our experiments unveiled involvement of JNK pathway as over expression of transcription factor Jun. NF $\kappa \mathrm{B}$ is a major transcription factors which is a key regulator of immune survival and anti-apoptotic response. $N F \kappa B 1$ and $N F \kappa B I A$ are seen over expressed in cancer cells. A 
Table 5 Summary of major up regulated genes and corresponding pathways involved in Ag-np exposure

\begin{tabular}{|c|c|c|c|}
\hline Gene (IMR-90) & Pathways & Genes (U251) & Pathways \\
\hline $\begin{array}{l}\text { Jun oncogene } \\
\text { (JUN) }\end{array}$ & $\begin{array}{l}\text { a) Mitogenic Pathway: } \\
\text { b) Wnt Pathway } \\
\text { c) PI3 Kinase/AKT } \\
\text { Pathway } \\
\text { d) Calcium and Protein } \\
\text { Kinase C Pathway }\end{array}$ & Jun oncogene (JUN) & $\begin{array}{l}\text { a) Mitogenic Pathway: } \\
\text { b) Wnt Pathway } \\
\text { c) PI3 Kinase/AKT } \\
\text { Pathway } \\
\text { d) Calcium and Protein } \\
\text { Kinase C Pathway }\end{array}$ \\
\hline $\begin{array}{l}\text { Bone morphogenetic protein } 2 \\
\text { (BMP2) }\end{array}$ & Hedgehog Pathway & Fibronectin 1 (FN1) & PI3 Kinase/AKT Pathway \\
\hline Interleukin 8 (IL8) & NF $\kappa$ B Pathway & $\begin{array}{l}\text { Nuclear factor of kappa light polypeptide gene } \\
\text { enhancer in B-cells } 1 \text { (p105) (NFkB1) }\end{array}$ & NF $\kappa$ B Pathway: \\
\hline $\begin{array}{l}\text { Colony stimulating factor } 2 \\
\text { (granulocyte-macrophage, CSF2) }\end{array}$ & $\begin{array}{l}\text { a) Calcium and Protein } \\
\text { Kinase C Pathway } \\
\text { b) LDL Pathway }\end{array}$ & $\begin{array}{l}\text { Nuclear factor of kappa light polypeptide gene } \\
\text { enhancer in B-cells inhibitor, alpha(NFKBIA) }\end{array}$ & NF $\kappa$ B Pathway \\
\hline \multirow[t]{3}{*}{$\begin{array}{l}\text { Transferrin receptor (p90, CD71), } \\
\text { (TFRC) }\end{array}$} & $\begin{array}{l}\text { Calcium and Protein } \\
\text { Kinase C Pathway }\end{array}$ & Transferrin receptor (p90, CD71), (TFRC) & $\begin{array}{l}\text { Calcium and Protein } \\
\text { Kinase C Pathway }\end{array}$ \\
\hline & & $\begin{array}{l}\text { Growth arrest and DNA-damage-inducible, alpha } \\
(\text { GADD45A) }\end{array}$ & p53 Pathway \\
\hline & & CCAAT/enhancer binding protein (C/EBP), beta (CEBPB) & Insulin Pathway \\
\hline
\end{tabular}

significant decrease in the expression of $\mathrm{NF} \kappa \mathrm{B}$ was observed in normal cells following Ag-np exposure. On the other hand an increase in the expression of MAPK was observed in normal cells. Jun up regulation was accompanied by up regulation of pro-inflammatory cytokine $I L-8$, granulocyte macrophage colony stimulating factor $(G M-C S F)$ in normal cells. Similar observations were reported in carbon nanoparticle toxicity where IL- 8 production was observed to be mediated by MAPkinase pathway [38]. Another regulator of signalling cascades which was differential expressed is Gadd 45. It is activated by cytokines and signal transduction pathways like MAPkinase pathway [39]. Once activated, Gadd 45 can trigger MAPKinase pathway as well.

Up regulation of Bax in cancer cells following Ag-np exposure, suggested induction of apoptotic stimuli through mitochondrial pathway. None of the apoptosis related genes were up regulated in normal cells. Down regulation of survivin, an apoptosis inhibitor protein (IAP) that blocks caspases renders it susceptible to apoptosis. Survivin is over expressed in cancer which increases resistance to apoptosis [40]. The differential gene expression profile observed following Ag-np exposure exhibits selective induction of pathways in normal and cancer cells which will determine the nature of response to nanoparticle exposure.

\section{Release of pro-inflammatory cytokines from silver nanoparticles treated fibroblasts}

The current investigation shows the ability of silver nanoparticles to trigger an inflammatory response based on induction of various pro-inflammatory cytokines and chemokines. A threefold increase in IL-6 levels was observed subsequent to exposure with silver nanoparticles. A similar increase in IL-6 levels following silver nanoparticle exposure recently reported corroborates with our observation [41]. IL-6, produced by a variety of cells including fibroblasts is a pleiotropic cytokine involved in the amplification of inflammatory responses [42,43]. Rapid increase in IL-6 levels is observed during

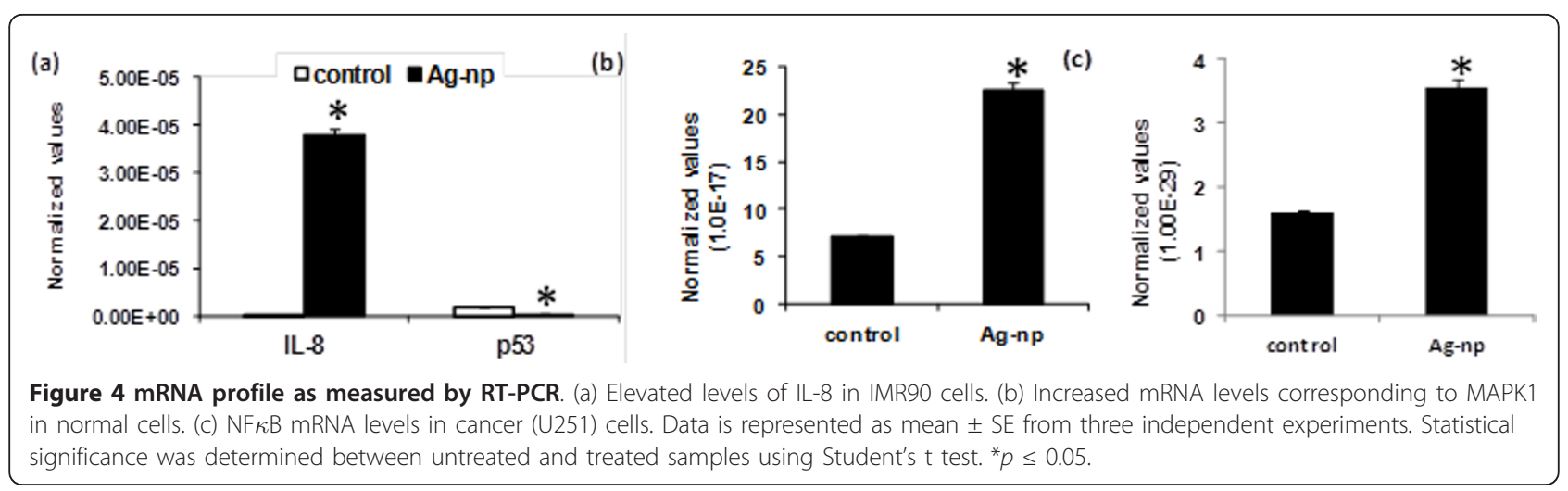



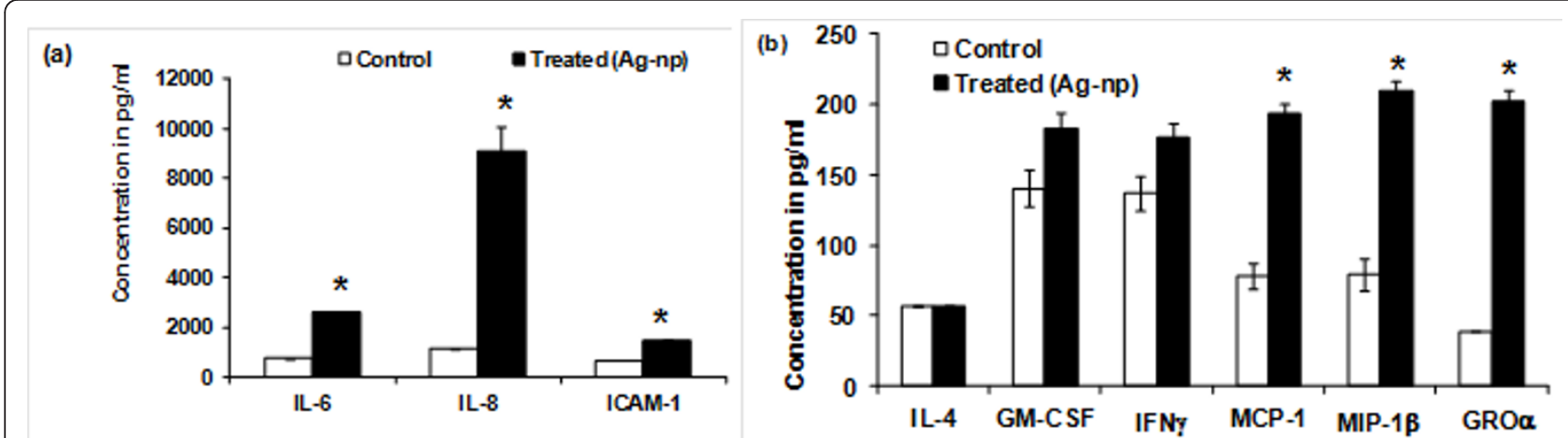

Figure 5 Silver nanoparticles induced cytokines and chemokines production in normal human lung fibroblasts (IMR90). The graphs indicate the production of cytokines and chemokines in pg/ml (mean \pm SD) by normal human fibroblasts after incubating with $400 \mu \mathrm{g} / \mathrm{mL}$ of silver nanoparticles for a period of 48 hours. The cytokine levels were measured in untreated cells (Control) and in cells treated with silver nanoparticles (treated (Ag-np)). Statistical significance was determined between untreated and treated samples using Student's $t$ test. ${ }^{*} p$ value $\leq 0.05$.

acute inflammatory responses due to injury, infection and stress $[42,43]$. It induces systemic effects affecting various organs and has been associated with a plethora of clinical conditions such as inflammatory lung disorders [44] and rheumatoid arthritis [45]. We have observed an eight fold increase in the levels of interleukin 8 , which is also produced by a variety of cells, including fibroblasts [46]. Inappropriate increase in the levels of IL- 8 has been associated with inflammatory disorders as well [47]. Intercellular adhesion molecule -1 (ICAM-1), MIP-1, MCP-1 (Monocyte chemoattractant protein - 1) and GRO-alpha known to be up regulated in inflammatory conditions was also seen following our silver nanoparticles exposure. These modulate chemotaxis, degranulation, phagocytosis and signalling mediator synthesis in cells $[48,49]$. Dysregulation of MIP-1, MCP-1 and GRO-alpha have been associated with a variety of inflammatory disorders [50-52]. We also observed an increase in the levels of GM-CSF and IFN $\gamma$. GM-CSF is involved in chemotaxis, phagocytosis and antigen presentation [53,54]. Increased levels have been associated with rheumatoid arthritis, chronic obstructive pulmonary disease and asthma [54]. IFN $\gamma$ responds against intracellular pathogens and tumour control. Abnormal expression and protein levels of IFN $\gamma$ have been associated with autoimmune and inflammatory conditions [55].

There are reports regarding the anti-inflammatory effects of silver nanoparticles $[15,56,57]$. However, the nature of the study (objectives, experimental conditions and endpoints) should be taken into consideration. Most of the studies were conducted on in vivo models (disease or wound healing models) with pre-existing injuries and utilized different combinations of silver nanoparticles coated/impregnated wound dressings. The objective of these studies was to analyze the additive therapeutic effects silver nanoparticles can have on the diseased or injured tissue. Those studies which reported similar findings using in-vitro studies evaluated the levels of these cytokines following an addition of a stimulus like LPS while pre or co-incubating with the silver nanoparticles. Our study was designed to evaluate the effect of these nanoparticles on normal unstimulated cells. Moreover, it should be noted that the source of the nanoparticles, concentration, size, technique and stabilizing agents involved in the preparation will all influence the response. To summarize, our study clearly shows an increase in the pro-inflammatory cytokines specific for human fibroblasts. This can be a unique response signature in these cells which should be taken into consideration. Though our study suggests an inflammatory response following Ag-np exposure, we cannot rule out the possibility of modifiers such as cell type used and nanoparticle used in the study.

Ag-np coated medical devices and wound dressings are already in the market. Human beings are constantly exposed to such commercial products the biological properties of which are still elusive. This study sheds light in to possible side effects of silver nanoparticles used in cosmetics, household products and in wound dressings. It is tempting to speculate that Ag-np impregnated wound dressings, catheters and other medical devices could induce similar response which may have detrimental effects in vivo as evidenced by the induction of DNA damage and inflammatory response by Ag-np in our study.

\section{Conclusion}

In summary, the genomics data suggests involvement of genotoxic stress and subsequent down regulation of DNA repair pathways in IMR-90 cells and U251 cells. Improper DNA repair could be a reason for accumulating cells at 
$\mathrm{S} / \mathrm{G}_{2} / \mathrm{M}$ phases of the cell cycle. Ag-np is able to down regulate many proteins involved in cell cycle progression and DNA repair by preventing their degradation possibly by surface adsorption. Ag-np can activate a variety of pathways including MAPK and $\mathrm{NF} \kappa \mathrm{B}$ pathways resulting in transcription of many genes involved in proliferation and inflammatory response. Our findings also suggest that only a small population of cells are undergoing apoptosis while majority are alive and were undergoing proliferation arrest. Our data reveal that Ag-np toxicity could trigger a detrimental inflammatory response. A more in-depth and multi parametric studies are recommended to elucidate the diverse role and effects of nanoparticles on different types of human cells including cancer cells. Such studies will further facilitate accurate toxicological profiling of nanoparticles and their potential therapeutic use in the management of different pathological conditions in humans.

\section{Methods}

Nanoparticles employed in this study $(6-20 \mathrm{~nm})$ were synthesised and characterised by us as described in our previous reports [26,58]. Extensive characterisations of the particles have been done through electron microscopy, dynamic light scattering and UV-visible spectroscopy.

\section{Cell culture and nanoparticle exposure}

Normal human lung fibroblasts (IMR-90) were purchased from Coriell cell repositories, USA. Cells were maintained in Minimum Essential Medium (MEM, Invitrogen, NY USA) supplemented with $15 \%$ foetal bovine serum (Hyclone, USA), 2\% essential amino acids and 1\% each of non-essential amino acid, vitamins and penicillin-streptomycin (GIBCO, Invitrogen, USA). The cells (passage $14 \pm 2$ ) were grown at $37^{\circ} \mathrm{C}$ in the presence of $5 \% \mathrm{CO}_{2}$ at $\log$ phase. Human glioblastoma cells were received from Dr. Masao Suzuki, National Institute of Radiological Sciences, Chiba, Japan and were maintained in Dulbecco's modified Eagles medium (DMEM, SigmaAldrich, MO, USA) supplemented with $10 \%$ foetal bovine serum (FBS, GIBCO, Invitrogen, USA) and 1\% penicillin streptomycin (Gibco, Invitrogen, NY, USA). Stock solutions were prepared in ultrapure water by dissolving $5 \mathrm{mg}$ of silver nanoparticles in $1 \mathrm{~mL}$ of ultra pure water. A uniform suspension was prepared by sonication.

\section{Isothermal titration calorimetry}

Isothermal titration calorimetry (ITC) computes the kinetics of molecular interactions based on the thermodynamics in the reaction. The interaction between the ligand and the binding partners is measured through subtle heat changes occurring in the reaction chamber.
The system consists of an injector, sample chamber and a reference cell. The ligand is injected at regular intervals into the chamber containing the second molecule. The sample chamber and the reference cells are kept at constant temperature. The binding between the ligand and the partner can either release or absorb heat. Endothermic (absorbs heat) reactions will prompt the system to provide heat in order to maintain the standard temperature in relation to the reference cell, whereas an exothermic reaction initiate absorption of excess heat by the system to stabilize the temperature. Heat changes per injections will be used to assess the interaction and calculate the binding affinity between the molecules. ITC experiments were carried out using a VP-ITC titration calorimetric system (Microcal Inc., MA, USA) operated at $25^{\circ} \mathrm{C}$. Each microcalorimetric titration experiment consisted of 60 successive injections of a constant volume $(5 \mu \mathrm{L} /$ injection) of cytosolic protein $(300 \mu \mathrm{g})$ in water to the reaction cell containing $(150 \mu \mathrm{g}$ in $1.8 \mathrm{~mL}) \mathrm{Ag}-\mathrm{np}$. The binding of starch to protein solutions in the absence of Ag-np and binding of starch capped Ag-np with genomic DNA was determined, using the same number of injections and concentration of proteins/DNA as in the titration experiments. Data analysis was carried out with Origin 7.0 software supplied with the instrument.

\section{Messenger RNA isolation and array hybridisation}

Cells were seeded at a density of $2 \times 10^{6}$ cells/T75 flasks and treated with $400 \mu \mathrm{g} / \mathrm{mL}$ of Ag-np for 48 hours. Cells were harvested in cold $1 \times$ phosphate buffered saline (PBS, $1^{\text {st }}$ Base, Singapore) and mRNA was isolated using Qiagen RNeasy mini kit (Qiagen, Hilden, Germany), following manufacturer's instruction. The concentration and integrity of mRNA was tested using Nanodrop spectrophotometer (Thermo Fischer Scientific, USA). The RNA from untreated and nanoparticle treated cells were used for hybridisation. The arrays (Oligo GEArray; SuperArray Bioscience Corporation, MD, USA) employed were human cell cycle oligo GEArray (OHS-020), human DNA damage signalling pathway oligo GEArray (OHS-029), human signal transduction pathway finder oligo GEArray (OHS-014) and human extracellular matrix and adhesion molecules oligo GEArray (OHS-013). Probing was done as per manufacturer's instructions. Briefly, complementary RNA (cRNA) was synthesised using TrueLabeling-AMP Linear RNA Amplification Kit (SuperArray Bioscience Corporation, Frederick, MD) as per manufacturer's instructions and biotinylated using Biotin-16-uridine-5'triphosphate (Roche, Germany). The biotinylated cRNA (3 $\mathrm{mg}$ ) was used for overnight hybridisation at $60^{\circ} \mathrm{C}$. The membrane was treated with alkaline phosphatase conjugated to streptavidin. Treated membranes were exposed to chemiluminescence reagent and image was captured on $\mathrm{X}$ - ray films. Image analysis was performed using GEArray 
expression analysis suite (SuperArray Bioscience Corporation, MD, USA). Normalisation was carried out using Rps27a, Gapdh, B2m, Hsp90ab1 and Beta actin. All values were normalised against housekeeping genes. Fold change is calculated as treated/control - 1 . Basal levels were normalised to 0 instead of 1 .

\section{Real-time Reverse Transcriptase Polymerase Chain Reaction (RT-PCR)}

RT-PCR was used to validate the results from array. RTPCR was done using LightCycler ${ }^{\circledR}$ RNA Amplification Kit SYBR Green I (Roche, Germany). Probes were designed using primer design utility. The details of genes employed and annealing temperature $\left(\mathrm{T}_{\mathrm{A}}\right)$ are included in Table 6 . DNA strands were amplified by denaturation at $95^{\circ} \mathrm{C}$ for 30 seconds followed by annealing of primers at specific temperatures for 15 seconds. Extension of the strands was done for $1 \mathrm{~min}$ at $72^{\circ} \mathrm{C}$. The experiments were conducted three times independently.

\section{Western blotting}

Cells density and exposure were maintained similar to array experiments. Cells were scraped and washed with cold $1 \times$ PBS. Protein was isolated by lysing the cells on ice for $20 \mathrm{~min}$ with radio immuno precipitation buffer (RIPA, $100 \mu \mathrm{L}$ ). The protein was isolated by centrifugation at $12,000 \mathrm{rpm}$ for $1 \mathrm{hr}$ at $4^{\circ} \mathrm{C}$ and quantified using Bradford assay kit with bovine serum albumin (BSA) standards (Biorad laboratories, CA, USA). Proteins $(40 \mu \mathrm{g})$ were separated in $10 \%$ poly-acrylamide gel and blotted on to nitrocellulose membrane (Hybond ECL, Amersham biosciences, UK), blocked in 5\% non-fat milk and incubated with primary antibodies (monoclonal anti mouse antibodies) against PCNA (dilution 1:800), cyclin B1 (1:1000), p21 (1:500), p53 (1:2000) phosphorylated p53 (phospho p53, cell signalling technologies Inc, Danvers, MA, USA 1:1000), PARP (1:1000) survivin (1:500), caspase 3 (1:500), and beta actin (Chemicon international, Temecula, CA, USA 1:5000). All antibodies were purchased from Santa
Cruz biotechnologies Inc (Santa Cruz, CA, USA) unless stated otherwise. Goat anti-mouse antibody tagged with horseradish peroxidase (Immuno pure, Pierce biotechnologies, Rockford, IL, USA, 1:5000) was used as secondary antibodies. Protein bands were visualized by chemiluminescence (ECL, Amersham biosciences, UK) and exposed to X-ray films (Pierce biotechnologies, Rockford, IL, USA). The intensity of bands was analysed using Kodak molecular imaging software (Kodak, USA) and normalised against actin. The normalised values were used for comparison with array data. Additional experiments were done using selected proteins (PCNA, cyclin B, p53, p21, caspase 3, PARP) for Ag-np concentrations 50 and $200 \mu \mathrm{g} / \mathrm{mL}$, to explore dose dependant effects.

\section{Immunofluorescence staining for $\gamma \mathrm{H} 2 \mathrm{AX}$}

Phosphorylation of histone H2AX occurs following a double strand DNA break, where ATM/ATR is activated. The phosphorylated protein binds to the DNA, at the damage site, aiding the repair process, which can be used as a biomarker for detecting ds DNA damage. The cells were plated on cover slips ( 0.4 million cells/well) in 6-well plates and treated with the nanoparticles $(25,50$ and $100 \mu \mathrm{g} / \mathrm{mL}$ of Ag-np-3; 80 and $160 \mu \mathrm{g} / \mathrm{mL}$ of Pt-np) for 2 hrs. Cells exposed to $10 \mu \mathrm{M} \mathrm{H}_{2} \mathrm{O}_{2}$ were used as positive controls. Following incubations, the cover slips were washed in PBS twice and fixed in $4 \%$ formaldehyde for $15 \mathrm{~min}$. After washing away excess formaldehyde, the cells were permeabilised in $0.2 \%$ triton $\times$ solution, blocked in $5 \%$ BSA $(1 \mathrm{hr})$ and incubated in primary Anti-phospho histone $\gamma \mathrm{H} 2 \mathrm{AX}$ mouse monoclonal antibody (Ser 139, JBW 103, Upstate biotechnology Inc., USA) for $1 \mathrm{hr}$. The cover slips were washed thrice in PBS to remove excess of primary antibody and stained with secondary antibody (anti-mouse antibody conjugated to FITC, eBiosciences, USA) for $1 \mathrm{hr}$. After washing away the excess of secondary antibodies, the cover slips were mounted in DAPI-vectashield. The images were captured under the DAPI-FITC filter of Zeiss Axioplan microscope. The experiment was repeated three

Table 6 Primer sequences and conditions employed in RT-PCR

\begin{tabular}{lcc}
\hline Gene & Primer sequence & $\mathbf{T}_{\mathbf{A}}\left(^{\circ} \mathbf{C}\right)$ \\
\hline p53 & 5'GGC CCA CTT CAC CGT ACT AA3' & 60 \\
& 5'GTG GTT TCA AGG CCA GAT GT3' & \\
Mitogen activated protein & 5'CCA CCC ATA TCT GGA GCA GT3' & 60 \\
kinase (MAPK1) & 5'CAG TCC TCT GAG CCC TTG TC 3' & \\
Interleukin-8 (IL-8) & 5'ATG ACT TCC AAG CTG GCC GTG GCT 3' & 61 \\
& 5'TCT CAG CCC TCT TCA AAA ACT TCT C 3' \\
Nuclear factor beta (NF $\kappa$ B) & 5' AGT TGA GGG GAC TाT CCC AGG 3' & 61 \\
18s Ribosomal subunit & 5' GCC TGG GAA AGT CCC CTC AAC T 3' & \\
& 5' GTA ACC CGT TGA ACC CCA TT-3' & 60 \\
\hline
\end{tabular}


times. Fifty DAPI-stained nucleus per sample were captured randomly with Zeiss Axioplan 2 imaging fluorescence microscope equipped with appropriate filters. Number of foci on each cell was recorded.

\section{Cytokine detection assay}

The effect of Ag-np on the levels of cytokines and chemokines of human lung fibroblasts were determined by collecting the supernatants from both the untreated and silver nanoparticles treated cultures were collected and stored in $-80^{\circ} \mathrm{C}$ until used. The cytokines were quantified using Bio-Plex ${ }^{\mathrm{TM}}$ Cytokine assay (Bio-Rad Laboratories, CA, USA). Premixed multiplex beads of the BioPlex human cytokine panel, which included 17 cytokines of choice (IL-1 $\beta$, IL-2, IL-4, IL-6, IL-7, IL-8, IL-16, IL17 , TNF $\alpha$, IFN $\gamma$, MCP-1 (CCL2), MIP-1 $\alpha$ (CCL3), MIP$1 \beta$, RANTES, ICAM-1, GM-CSF, GRO $\alpha$ ) were used and the assay was performed thrice by strictly adhering to the manufacturer's instructions. The data were analysed using the Bio-Plex Manager 4.0 software (Bio-Rad Laboratories, CA, USA).

\section{Acknowledgements}

The authors thank Mr. Aik Kia Khaw for his help in performing super array. We thank Mr. Karthik for his support in performing and analysing ITC. We acknowledge facilities support by the NUS-Nanoscience and Nanotechnology Initiative (NUSNNI), Department of Chemistry and Department of Physiology. This study was supported by grants from the Academic Research Fund, Ministry of Education, Singapore (T206B3108; WBS: 185-000-153-112) to MPH.

\section{Author details}

${ }^{1}$ Department of Chemistry, Faculty of Science, 3 Science Drive 3, National University of Singapore, 117543, Singapore. ${ }^{2}$ Department of Physiology, Yong Loo Lin School of Medicine, 2, Medical Drive, National University of Singapore, 117597, Singapore. ${ }^{3}$ Tembusu College, National University of Singapore, 28 College Avenue East, 138598, Singapore.

\section{Authors' contributions}

AR, MPH and SV designed the experiments. AR performed nanoparticle synthesis, ITC, western blots and super array and conducted the experiments. GB analyzed ITC data. SS conducted and analyzed cytokine profiling. AR and HKL wrote and edited the manuscript. All the authors approved the final version of the manuscript.

\section{Competing interests}

The authors declare that they have no competing interests.

Received: 31 August 2011 Accepted: 10 February 2012

Published: 10 February 2012

\section{References}

1. Singh S, Nalwa HS: Nanotechnology and health safety-toxicity and risk assessments of nanostructured materials on human health. JNanosciNanotechnol 2007, 7:3048-3070.

2. Navarro E, Baun A, Behra R, Hartmann NB, Filser J, Miao AJ, Quigg A, Santschi PH, Sigg L: Environmental behavior and ecotoxicity of engineered nanoparticles to algae, plants, and fungi. Ecotoxicology 2008, 17:372-386.

3. Xia T, Kovochich M, Liong M, Zink Jl, Nel AE: Cationic polystyrene nanosphere toxicity depends on cell-specific endocytic and mitochondrial injury pathways. ACS nano 2008, 2:85-96.
4. Awazu K, Fujimaki M, Rockstuhl C, Tominaga J, Murakami H, Ohki Y, Yoshida N, Watanabe T: A plasmonic photocatalyst consisting of silver nanoparticles embedded in titanium dioxide. JAmChemSoC 2008, 130:1676-1680.

5. Chen X, Schluesener HJ: Nanosilver: a nanoproduct in medical application. ToxicolLett 2008, 176:1-12.

6. Endo T, Ikeda R, Yanagida Y, Hatsuzawa T: Stimuli-responsive hydrogelsilver nanoparticles composite for development of localized surface plasmon resonance-based optical biosensor. AnalChimActa 2008, 611:205-211

7. Pedroso MS, Pinho GL, Rodrigues SC, Bianchini A: Mechanism of acute silver toxicity in the euryhaline copepod Acartia tonsa. AquatToxicol 2007, 82:173-180.

8. Wataha JC, Hanks CT, Sun Z: In vitro reaction of macrophages to metal ions from dental biomaterials. DentMater 1995, 11:239-245.

9. AshaRani PV, Low Kah Mun G, Hande MP, Valiyaveettil S: Cytotoxicity and genotoxicity of silver nanoparticles in human cells. ACS Nano 2009, 3:279-290.

10. Kim S, Choi JE, Choi J, Chung KH, Park K, Yi J, Ryu DY: Oxidative stressdependent toxicity of silver nanoparticles in human hepatoma cells. Toxicol In Vitro 2009, 23:1076-1084.

11. Foldbjerg R, Olesen P, Hougaard M, Dang DA, Hoffmann HJ, Autrup H: PVPcoated silver nanoparticles and silver ions induce reactive oxygen species, apoptosis and necrosis in THP-1 monocytes. Toxicol Lett 2009, 190:156-162.

12. AshaRani PV, LianWu Y, Gong Z, Valiyaveettil S: Toxicity of silver nanoparticles in zebrafish models. Nanotechnology 2008, 19:255102.

13. Kumari M, Mukherjee A, Chandrasekaran N: Genotoxicity of silver nanoparticles in Allium cepa. Sci Total Environ 2009, 407:5243-5246.

14. Chung YC, Chen $\mathrm{IH}$, Chen $\mathrm{CJ}$ : The surface modification of silver nanoparticles by phosphoryl disulfides for improved biocompatibility and intracellular uptake. Biomaterials 2008, 29:1807-1816.

15. Nadworny PL, Wang J, Tredget EE, Burrell RE: Anti-inflammatory activity of nanocrystalline silver in a porcine contact dermatitis model. Nanomedicine 2008, 4:241-251.

16. Shin SH, Ye MK, Kim HS, Kang HS: The effects of nano-silver on the proliferation and cytokine expression by peripheral blood mononuclear cells. Int/mmunopharmacol 2007, 7:1813-1818.

17. Chen $D, X i T$, Bai J: Biological effects induced by nanosilver particles: in vivo study. BiomedMater 2007, 2:S126-S128.

18. Salamon A, Toldy E: Role of fibroblasts in physiologic, reparative and pathologic processes. OrvHetil 2007, 148:1683-1690.

19. Darby IA, Hewitson TD: Fibroblast differentiation in wound healing and fibrosis. IntRevCytol 2007, 257:143-179.

20. Schins RP: Mechanisms of genotoxicity of particles and fibers. Inhal Toxicol 2002, 14:57-78.

21. Monleau M, De Meo M, Paquet F, Chazel V, Dumenil G, DonnadieuClaraz M: Genotoxic and inflammatory effects of depleted uranium particles inhaled by rats. Toxicol Sci United States 2006, 89:287-295.

22. Schins RP, Knaapen AM: Genotoxicity of poorly soluble particles. Inhal Toxicol United States 2007, 19(Suppl 1):189-198.

23. Nishigori C, Yarosh DB, Ullrich SE, Vink AA, Bucana CD, Roza L, Kripke ML: Evidence that DNA damage triggers interleukin 10 cytokine production in UV-irradiated murine keratinocytes. Proc Natl Acad Sci USA 1996, 93:10354-10359.

24. O'Connor A, Nishigori C, Yarosh D, Alas L, Kibitel J, Burley L, Cox P, Bucana C, Ullrich S, Kripke M: DNA double strand breaks in epidermal cells cause immune suppression in vivo and cytokine production in vitro. J Immunol 1996, 157:271-278.

25. Lynch I, Dawson KA: Protein-nanoparticle interactions. Nanotoday 2008, 3:40.

26. AshaRani PV, Low Kah MG, Hande MP, Valiyaveettil S: Cytotoxicity and genotoxicity of silver nanoparticles in human cells. ACS nano 2009, 3:279-290.

27. O'Reilly MA, Staversky RJ, Watkins RH, Maniscalco WM, Keng PC: p53independent induction of GADD45 and GADD153 in mouse lungs exposed to hyperoxia. AmJPhysiol Lung Cell MolPhysiol 2000, 278 : L552-L559.

28. Jin S, Tong T, Fan W, Fan F, Antinore MJ, Zhu X, Mazzacurati L, Li X, Petrik KL, Rajasekaran B, et al: GADD45-induced cell cycle G2-M arrest 
associates with altered subcellular distribution of cyclin B1 and is independent of p38 kinase activity. Oncogene 2002, 21:8696-8704.

29. Zhang HS, Gavin M, Dahiya A, Postigo AA, Ma D, Luo RX, Harbour JW, Dean DC: Exit from $\mathrm{G} 1$ and $S$ phase of the cell cycle is regulated by repressor complexes containing HDAC-Rb-hSWI/SNF and Rb-hSWI/SNF. Cell 2000, 101:79-89.

30. Yang JJ: Mixed lineage kinase ZAK utilizing MKK7 and not MKK4 to activate the c-Jun $\mathrm{N}$-terminal kinase and playing a role in the cell arrest. BiochemBiophysResCommun 2002, 297:105-110.

31. Fotedar R, Bendjennat M, Fotedar A: Role of p21WAF1 in the cellular response to UV. Cell Cycle 2004, 3:134-137.

32. Cuadrado M, Martinez-Pastor B, Murga M, Toledo LI, Gutierrez-Martinez P, Lopez E, Fernandez-Capetillo O: ATM regulates ATR chromatin loading in response to DNA double-strand breaks. JExpMed 2006, 203:297-303.

33. Shaul Y, Ben-Yehoyada M: Role of c-Abl in the DNA damage stress response. Cell Res 2005, 15:33-35.

34. Slupianek A, Nowicki MO, Koptyra M, Skorski T: BCR/ABL modifies the kinetics and fidelity of DNA double-strand breaks repair in hematopoietic cells. DNA Repair (Amst) Netherlands 2006, 5:243-250.

35. Moldovan GL, Pfander B, Jentsch S: PCNA, the maestro of the replication fork. Cell 2007, 129:665-679.

36. Mousa SA: Cell adhesion molecules: potential therapeutic \& diagnostic implications. MolBiotechnol 2008, 38:33-40.

37. Hsin YH, Chen CF, Huang S, Shih TS, Lai PS, Chueh PJ: The apoptotic effect of nanosilver is mediated by a ROS- and JNK-dependent mechanism involving the mitochondrial pathway in NIH3T3 cells. ToxicolLett 2008, 179:130-139.

38. Kim YM, Reed W, Lenz AG, Jaspers I, Silbajoris R, Nick HS, Samet JM: Ultrafine carbon particles induce interleukin-8 gene transcription and p38 MAPK activation in normal human bronchial epithelial cells. AmJPhysiol Lung Cell MolPhysiol 2005, 288:L432-L441.

39. Tong T, Fan W, Zhao H, Jin S, Fan F, Blanck P, Alomo I, Rajasekaran B, Liu Y, Holbrook NJ, Zhan Q: Involvement of the MAP kinase pathways in induction of GADD45 following UV radiation. ExpCell Res 2001, 269:64-72.

40. Pennati M, Folini M, Zaffaroni N: Targeting survivin in cancer therapy. ExpertOpinTherTargets 2008, 12:463-476.

41. Castillo PM, Herrera JL, Fernandez-Montesinos R, Caro C, Zaderenko AP, Mejias JA, Pozo D: Tiopronin monolayer-protected silver nanoparticles modulate IL- 6 secretion mediated by Toll-like receptor ligands. Nanomed 2008, 3:627-635.

42. Kamimura D, Ishihara K, Hirano T: IL-6 signal transduction and its physiological roles: the signal orchestration model. RevPhysiol BiochemPharmacol 2003, 149:1-38.

43. Kishimoto T: Interleukin-6: discovery of a pleiotropic cytokine. Arthritis ResTher 2006, 8(Suppl 2):S2.

44. Wong CK, Ho CY, Ko FW, Chan CH, Ho AS, Hui DS, Lam CW: Proinflammatory cytokines (IL-17, IL-6, IL-18 and IL-12) and Th cytokines (IFN-gamma, IL-4, IL-10 and IL-13) in patients with allergic asthma. Clin Explmmunol 2001, 125:177-183.

45. Hirano T, Matsuda T, Turner M, Miyasaka N, Buchan G, Tang B, Sato K, Shimizu M, Maini R, Feldmann M: Excessive production of interleukin 6/B cell stimulatory factor-2 in rheumatoid arthritis. EurJ Immunol 1988, 18:1797-1801.

46. Harada A, Sekido N, Akahoshi T, Wada T, Mukaida N, Matsushima K: Essential involvement of interleukin-8 (IL-8) in acute inflammation. J LeukocBiol 1994, 56:559-564.

47. Brennan FM, Zachariae CO, Chantry D, Larsen CG, Turner M, Maini RN, Matsushima K, Feldmann M: Detection of interleukin 8 biological activity in synovial fluids from patients with rheumatoid arthritis and production of interleukin 8 mRNA by isolated synovial cells. EurJ Immunol 1990, 20:2141-2144

48. Maurer M, von SE: Macrophage inflammatory protein-1. IntJ BiochemCell Biol 2004, 36:1882-1886.

49. Staunton DE, Dustin ML, Springer TA: Functional cloning of ICAM-2, a cell adhesion ligand for LFA-1 homologous to ICAM-1. Nature 1989, 339:61-64

50. Murdoch C, Finn A: Chemokine receptors and their role in inflammation and infectious diseases. Blood 2000, 95:3032-3043.

51. Sousa AR, Lane SJ, Nakhosteen JA, Yoshimura T, Lee TH, Poston RN: Increased expression of the monocyte chemoattractant protein-1 in bronchial tissue from asthmatic subjects. AmJ RespirCell MolBiol 1994, 10:142-147.

52. Traves SL, Culpitt SV, Russell RE, Barnes PJ, Donnelly LE: Increased levels of the chemokines GROalpha and MCP-1 in sputum samples from patients with COPD. Thorax 2002, 57:590-595.

53. Gasson JC: Molecular physiology of granulocyte-macrophage colonystimulating factor. Blood 1991, 77:1131-1145.

54. Hamilton JA, Anderson GP: GM-CSF Biology. Growth Factors 2004, 22:225-231.

55. Schoenborn JR, Wilson CB: Regulation of interferon-gamma during innate and adaptive immune responses. Adv Immunol 2007, 96:41-101.

56. Tan J, Wong KK, Ho CM, Lok CN, Yu WY, Che CM, Chiu JF, Tam PK: Topical delivery of silver nanoparticles promotes wound healing. Chem Med Chem 2007, 2:129-136.

57. Wong KK, Cheung SO, Huang L, Niu J, Tao C, Ho CM, Che CM, Tam PK: Further evidence of the anti-inflammatory effects of silver nanoparticles. Chem Med Chem 2009, 497:1129-1135.

58. Asharani PV, Sethu S, Vadukumpully S, Zhong SP, Lim CT, Hande MP, Valiyaveettil S: Investigations on the Structural Damage in Human Erythrocytes Exposed to Silver, Gold, and Platinum Nanoparticles. Adv Funct Mater 2010, 20:1233-1242.

doi:10.1186/2041-9414-3-2

Cite this article as: AshaRani et al:: Differential regulation of intracellular factors mediating cell cycle, DNA repair and inflammation following exposure to silver nanoparticles in human cells. Genome Integrity 2012 $3: 2$.

\section{Submit your next manuscript to BioMed Central and take full advantage of:}

- Convenient online submission

- Thorough peer review

- No space constraints or color figure charges

- Immediate publication on acceptance

- Inclusion in PubMed, CAS, Scopus and Google Scholar

- Research which is freely available for redistribution

Submit your manuscript at www.biomedcentral.com/submit
Biomed Central 